\title{
Obsessive-Compulsive Disorder Reconsidered
}

Christopher J. McDougle, MD

Yale University School of Medicine

Follow this and additional works at: https://jdc.jefferson.edu/jeffjpsychiatry

Part of the Psychiatry Commons

Let us know how access to this document benefits you

\section{Recommended Citation}

McDougle, MD, Christopher J. (1988) "Obsessive-Compulsive Disorder Reconsidered," Jefferson Journal of Psychiatry. Vol. 6 : Iss. 1 , Article 12.

DOI: https://doi.org/10.29046/JJP.006.1.011

Available at: https://jdc.jefferson.edu/jeffjpsychiatry/vol6/iss1/12

This Article is brought to you for free and open access by the Jefferson Digital Commons. The Jefferson Digital Commons is a service of Thomas Jefferson University's Center for Teaching and Learning (CTL). The Commons is a showcase for Jefferson books and journals, peer-reviewed scholarly publications, unique historical collections from the University archives, and teaching tools. The Jefferson Digital Commons allows researchers and interested readers anywhere in the world to learn about and keep up to date with Jefferson scholarship. This article has been accepted for inclusion in Jefferson Journal of Psychiatry by an authorized administrator of the Jefferson Digital Commons. For more information, please contact: JeffersonDigitalCommons@jefferson.edu. 


\title{
Book Review
}

\section{Obsessive-Compulsive Disorder Reconsidered}

\author{
OBSESSIVE-COMPULSIVE DISORDERS: THEORY \& MANAGEMENT \\ Edited by Michael A. Jenike, Lee Baer, William E. Minichiello \\ Littleton, Mass, PSG Publishing Company, Inc.
}

1986. 196 pages, $\$ 24.50$

\section{Christopher J. McDougle, M.D.}

Recently renewed interest in obsessive-compulsive disorder (OCD) has been generated in the psychiatric community. This change is based on new information which suggests OCD is neither as rare (1) nor as untreatable (2) as once believed.

The Epidemiology Catchment Area (ECA) study (1) found OCD twenty times more common than previously thought, with a lifetime prevalence of $2-3 \%$. In a review of the literature, Krystal, et al (2) suggest that drastic treatments for OCD, such as frontal leukotomy, might be avoided through the use of serotonergically active antidepressants such as clomipramine, fluoxetine or fluvoxamine. With these new advances, perspectives on OCD have changed; clinicians need to become better informed about the features of and treatments for this disorder. In Obsessive-Compulsive Disorders: Theory and Management, Jenike and his associates highlight an interdisciplinary approach which provides an excellent introduction to OCD for the general psychiatric clinician.

The book varies in the depth and quality of the information it presents. In the introductory chapter, Baer and Jenike review basic definitions of obsessions and compulsions as well as the current nosological approaches to OCD. They point out that although a subgroup of their OCD patients suffer from concomitant schizotypal personality disorder, OCD is not typically a psychotic disorder. Their review is consistent with an emerging literature (3) which has observed psychotic features in some patients with OCD, despite its place among the anxiety disorders.

After these introductory definitions, Jenike attempts to summarize the

Dr. McDougle is a Postdoctoral Fellow in Psychiatry at the Clinical Neuroscience Research Unit, Yale University School of Medicine. 
etiologic theories for OCD. He cogently reviews many factors influencing the onset and course of OCD including infectious, traumatic, neoplastic and neurodevelopmental contributions. Unfortunately, he fails to mention the leading neurobiological theories for the pathogenesis of OCD, which involve abnormalities in serotonergic and dopaminergic function. Such an omission leaves an important gap in a clinician's ability to understand and to treat this illness.

Rasmussen and Tsuang present a comprehensive review of the epidemiology of OCD. This compendium thoroughly addresses demographic variables, phenomenologic and clinical features, follow-up studies, and family and genetic studies. To date, there have been no studies of OCD in monozygotic twins raised apart or in adopted-away children of adult OCD patients. However, the ECA data suggests that the prevalence of OCD in the general population is twice that of schizophrenia, making possible adoption studies similar to those undertaken by Kety, et al in schizophrenia (4). Such information would provide important data on the genetic factors underlying the development of the disorder.

Any discussion would be incomplete without consideration of the behavioral perspective on OCD. Baer and Minichiello explore both experimental and clinical approaches. They highlight a study that tests Wolpe's modified anxietyreduction hypothesis by measuring subjective anxiety and autonomic arousal in two symptomatically-distinct groups of OCD patients, checkers and cleaners. Situations which evoked compulsive rituals increased physiologic and subjective measures of anxiety, although checkers showed smaller increases than cleaners. Engaging in ritualistic behavior generally decreased both measures of anxiety. However, in seven of 36 trials, anxiety was increased in checkers despite engaging in ritualistic behaviors. Baer and Minichiello strengthen their discussion of the clinical technique of in vivo exposure and response prevention by incorporating these experimental findings. In addition, their delineation of the steps involved in performing a careful behavioral analysis warrants particular attention.

Jenike nicely reviews somatic treatments for OCD, including the use of medications, ECT and psychosurgery. Although this chapter misses some of the most recent advances in OCD treatment, such as lithium augmentation of fluvoxamine (2), it provides a useful, clinically-based introduction to pharmacologic treatments.

Although some readers may take issue with Jenike's statement that traditional psychodynamic psychotherapy is not an effective treatment for patients with OCD, there is no data-based evidence of its efficacy available. However, psychodynamic psychotherapy can be a useful adjunct to behavioral and pharmacologic approaches when specific techniques are employed. For example, Salzman (5) feels that the central issue in treating the obsessional patient is the formation of a therapeutic relationship. Jenike also suggests that individuals with OCD must have a strong conviction about the need to change, and trust in the therapist before making behavior changes during therapy. He believes that 
the therapist needs to be more active than is encouraged in traditional psychodynamic psychotherapy in order to interrupt the patient's maladaptive defense mechanisms. Other therapeutic strategies which focus on the expression of feelings, relaxing control of environmental change, and alleviating inappropriate guilt and anxiety, also generally facilitate the development of a therapeutic alliance.

Recent evidence has suggested a genetic linkage between OCD and Tourette's Syndrome (TS). This hypothesis is consistent with more recent findings. Although the mode of transmission is unclear at this time for either syndrome, Pauls, et al recently showed that $25 \%$ of first-degree relatives of over 200 TS patients meet standardized criteria for OCD $(6,7)$. There is no increase in the incidence of OCD in relatives of TS patients who manifest OCD symptoms as compared to TS patients without OCD symptoms. This finding led Green and Pitman, the authors of this chapter, to conclude that the manifestations of obsessions and compulsions in some individuals and tics in others may be determined by a common genetic factor. Support for this conclusion comes from more recent work by Green and Pitman (8), who compared TS and OCD, showing that the rate of positive family history for tics in OCD patients without tics themselves, was found to be as high as the rate for OCD patients with tics.

The chapter by Jenike on the neurobiology of OCD is one of the weakest in the book. Rather than addressing fundamental neurobiological theories pertaining to the pathophysiology of OCD, he focuses on clinical biological markers which may be useful in diagnosis. A discussion of the contributions of serotonin and dopamine systems to the pathogenesis of OCD would have provided a useful framework for understanding the mechanisms of action of the new pharmacotherapies for this disorder.

A step-by-step approach to the assessment of OCD patients is presented in the final chapter. This diagnostic interview includes a Behavioral Analysis Questionnaire, a Mental Status Questionnaire and the Maudsley ObsessionalCompulsive Inventory, all utilized by the editors in the Obsessive-Compulsive Disorders Clinic at the Massachusetts General Hospital. This scheme will prove useful to clinicians in identifying OCD patients and designing appropriate treatment strategies.

The editors state that the purpose of this book is to present the current "state of the art" in the treatment of OCD. In general, they accomplish this task by utilizing an interdisciplinary effort addressing behavioral, pharmacologic, psychotherapeutic and psychosurgical approaches. On the whole, the text is well written, readable, and extensively referenced through 1986 . It would be a useful addition to the library of psychiatry and neurology residents and clinicians, as well as behavior therapists. With the possible exception of the neurobiological section, the text provides a good general introduction to OCD. Such an introduction is particularly critical to most psychiatric residents, who may find that training in the management of this surprisingly common disorder is often lacking due to its previous obscurity. 


\section{REFERENCES}

1. Robins LN, Helzer JE, Weissman MM, et al: Lifetime prevalence of specific psychiatric disorders in three sites. Arch Gen Psych 1984; 41:958-967

2. Krystal JH, Goodman WK, Woods SW, Charney DS: Anxiety Disorders, in Outpatient Psychiatry: Diagnosis and Treatment (2nd edition), Edited by Lazare A, Baltimore, Williams and Wilkins Press (in press)

3. Insel TR, Akiskal HS: Obsessive-compulsive disorder with psychotic features: A phenomenologic analysis. Am J Psych 1986; 143:1527-1533

4. Kety SS, Rosenthal D, Wender PM, et al: The types and prevalence of mental illness in the biological and adoptive families of adopted schizophrenics. J Psychiatr Res 1968; 6:345-362

5. Salzman L: Psychoanalytic theory of the obsessional patient. Curr Psychiatr Ther 1983; 9:53-59

6. Pauls DL, Kruger SD, Leckman JF, et al: The risk of Tourette Syndrome and chronic multiple tics among relatives of Tourette Syndrome patients obtained by direct interview. J Am Acad Child Psych 1984; 23:134-137

7. Pauls DL, Towbin KE, Leckman JF, et al: Gilles de la Tourette's syndrome and obsessive-compulsive disorder: Evidence supporting an etiological relationship. Arch Gen Psych 1986; 43:1180-1182

8. Pitman RK, Green RC, Jenike MA, et al: Clinical comparison of Tourette's disorder and obsessive-compulsive disorder. Am J Psych 1987; 144:1161-1171 